\title{
Acoustic Emission Behavior during Tensile Tests of Low Carbon Steel Welds
}

\author{
C. S. LEE, J. H. HUH, D. M. LI and D. H. SHIN ${ }^{1)}$
}

Center for Advanced Aerospace Materials, Pohang University of Science and Technology San 31, Hyoja-dong, Pohang 790-784, Korea. 1) Department of Metallurgy and Materials Science, Hanyang University, Ansan, Kyunggi-Do, 425-791, Korea.

(Received on September 24, 1998; accepted in final form on December 10, 1998)

\begin{abstract}
The tensile behavior of a low-carbon low alloy steel has been studied by means of acoustic emission $(A E)$ technique for the welded joint consisting of three regions (the base metal, the heat affected zone (HAZ) and the weld metal). The AE characteristics of the base metal are distinctly different from those of the HAZ and the weld metal. For the base metal with a ferrite-pearlite microstructure, most of the AE events occur around the yield point, mainly due to the dislocation movements associated with the tensile deformation. For the HAZ and the weld metal, a second AE peak with higher energy is evident after yielding, in addition to the $A E$ peak occurring around the yield point. The second $A E$ peak is attributed to the presence of martensite, as examined by the AE results obtained from the base metal heat-treated to have different martensite volume fractions. The ferrite-martensite interfacial debonding and/or the martensitic plate cracking act as the principal sources of the second AE peak, as confirmed by the microstructural observations and the frequency spectrum analyses.
\end{abstract}

KEY WORDS: acoustic emission; welded joint; heat affected zone; weld metal; cracking; AE peak.

\section{Introduction}

Fast increasing height of modern buildings makes it necessary to improve the performance of the structural steels in order to resist earthquakes and strong winds. Therefore the steels served for these purposes have to possess excellent properties such as strength, toughness and weldability. In recent years the steels treated via the thermo-mechanically controlled process (TMCP) are especially attractive for their high strength and high toughness due to their fine grain sizes and low carbon contents. ${ }^{11}$ However, efforts are still to be made to solve the problems involved in the welds because mechanical properties, especially toughness, ${ }^{2)}$ are seriously deteriorated in regions of the heat-affected zone (HAZ) and the weld metal, due to coarsened grains and transformed microstructures.

As a non-destructive evaluation techniques, acoustic emission (AE) method has been widely utilized in recent decades to inspect the atomic power plants, bridges and fuel tanks owing to its capability of real-time monitoring. ${ }^{3)}$ Since AE is highly sensitive to some specific microevents in local areas, e.g. dislocation movement and multiplication, microcrack initiation and growth, and interfacial cracking, the AE method is useful in identifying the origin, magnitude and distribution of the source that causes the characteristic AE events. Advances have been made in studies using the AE method in characterizing the deformation behavior, ${ }^{4-9)}$ the interfacial debonding/cracking ${ }^{10-12)}$ and the micro-void coalescence or crack growth ${ }^{13)}$ in steels and other non-ferrous alloys. In evaluating the mechanical behavior of welds, although there are significant progresses in the AE investigations, ${ }^{14-16)}$ further experimental and theoretical studies are still needed to get a better understanding of the correlation between the AE behavior and microstructure. So far, there has been no systematic investigation on the AE behavior of TMCP welds. Consequently the present study is aimed to investigate the $\mathrm{AE}$ behavior during tensile deformation of welded joints of TMCP steel and to correlate the $\mathrm{AE}$ behavior with the specific microstructures in the base metal, the HAZ and the weld metal, as well as the transformed microstructures reproduced by heat treatment.

\section{Experimental Procedures}

The material used in the present study was a TMCP steel with a chemical composition of (in weight percent) $0.14 \mathrm{C}, 0.23 \mathrm{Si}, 1.23 \mathrm{Mn}, 0.0117 \mathrm{P}, 0.003 \mathrm{~S}, 0.033 \mathrm{Cr}$, $0.015 \mathrm{Ti}$, and balance $\mathrm{Fe}$. The as-received steel was in the form of $48 \mathrm{~mm}$ thick plate. A submerged arc welding (SAW) method was used to weld the steel joints, with an arc voltage of $36 \mathrm{~V}$, a welding current of $980 \mathrm{~A}$ and a heat input of $9.2 \mathrm{~kJ} / \mathrm{mm}$. No heat-treatment was conducted after welding. The tensile specimens were made from each region in the base metal, the HAZ and the weld metal, respectively. Besides these specimens, 


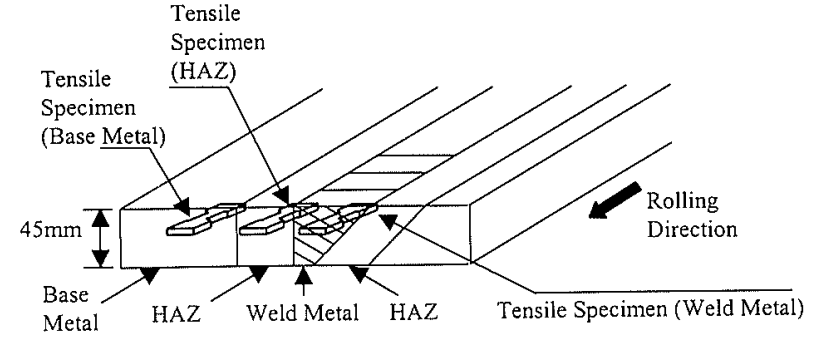

(a)

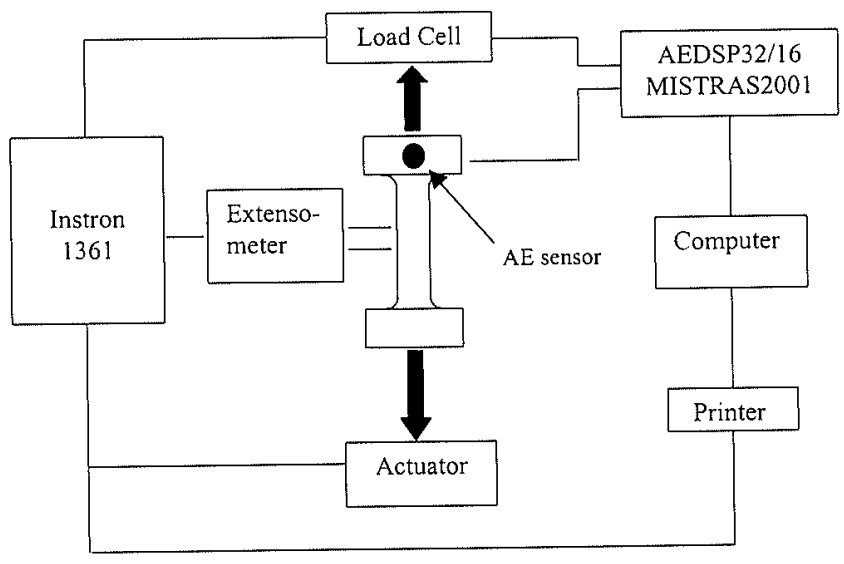

(b)

Fig. 1. Schematic diagrams showing (a) the preparation of tensile specimens from the welding plate and (b) the location of sensor during the tensile tests

another set of samples was made to simulate the microstructural changes in the HAZ and the weld metal. They were heated to $760,800,830$ and $860^{\circ} \mathrm{C}$, respectively, for $1.5 \mathrm{~h}$ and then quenched in water, to produce different amount of transformed martensite. They are hereafter referred to as $\mathrm{HT}_{1}, \mathrm{HT}_{2}, \mathrm{HT}_{3}$ and $\mathrm{HT}_{4}$, respectively. The volume fraction of the martensite was measured using the Mössbauer analysis to be $26,43,61$ and $82 \%$, respectively, corresponding to the increase in heating temperatures given above. The microstructures were observed under a scanning electron microscope (SEM).

The tensile specimens were prepared according to the relevant ASTM code and they had a width of $6.25 \mathrm{~mm}$, a thickness of $3 \mathrm{~mm}$ and a gauge length of $25 \mathrm{~mm}$. The specimens were cut from the base metal, the HAZ and the weld metal regions, respectively, with the tensile axis in the rolling direction as shown in Fig. 1(a). The tensile tests were conducted at room temperature using an Instron 1361 testing machine with a cross-head speed of $0.27 \mathrm{~mm} / \mathrm{min}$. The AE analysis was performed using the AE detector (AEDSP-32/16) made by PAC Co., with the resonance type sensor R15, nominal center frequency of which was about $153 \mathrm{kHz}$. The data processing was done under the condition of a pre-amplification of $40 \mathrm{~dB}$ plus a main amplification of $40 \mathrm{~dB}$, giving a total amplification of $80 \mathrm{~dB}$. The sensor was coupled to the polished jig using a grease under constant pressure. To remove
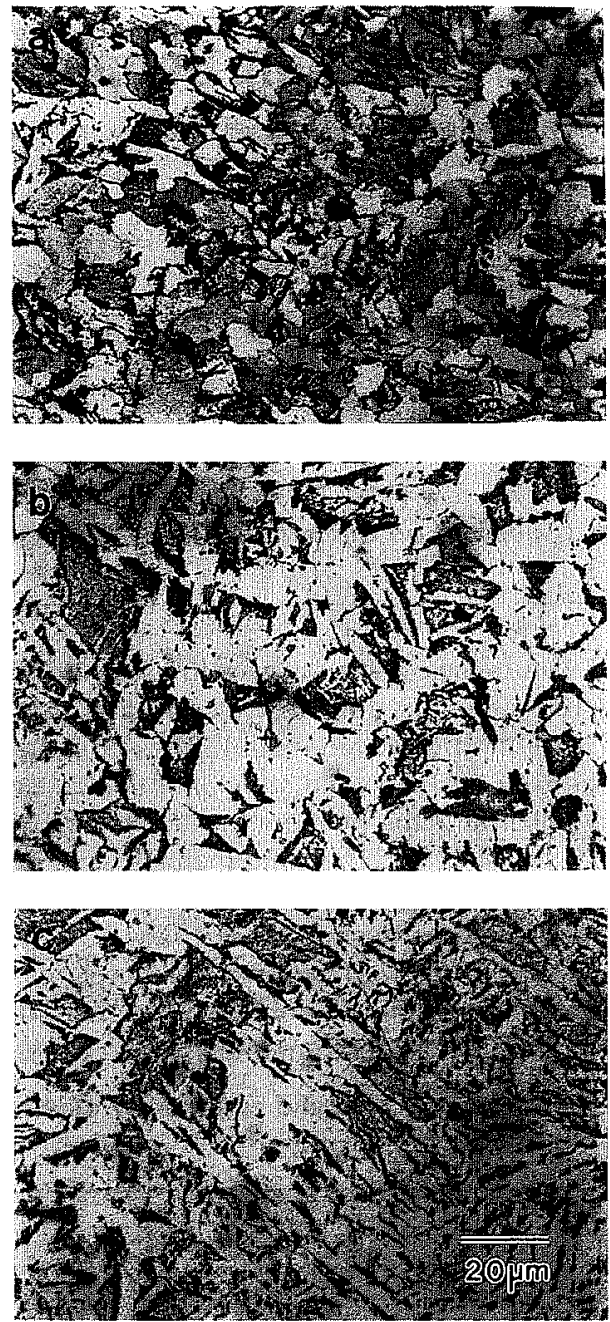

Fig. 2. Optical micrographs showing microstructures in (a) base metal, (b) HAZ and (c) weld metal.

the noise from actuator, etc., a threshold amplitude was specified to be $30 \mathrm{~dB}$, which was determined in the preliminary tests by using an oscilloscope. The jig pin is coated with a layer of grease to minimize the friction between the specimen and the jig. The AE data acquisition was realized by means of the MISTRAS 2001 program operated during the tensile tests.

\section{Results and Discussion}

\subsection{Microstructures and Tensile Properties}

The microstructures of three different regions of welds are shown in Fig. 2. The base metal is composed of ferrite and pearlite (Fig. 2(a)). The microstructure in the HAZ represents relatively coarse grains (Fig. 2(b)), which also includes the martensite-austenite (M-A) constituent, upper bainite and martensite formed during the heating-cooling cycle of welding. According to the previous investigation on carbon-manganese steel, ${ }^{17)}$ the martensitic structure has frequently been observed to form in the welded zone. In the region of the weld metal, the microstructural constituents similar to those in the HAZ also exist, but typically an area of coarse columnar microstructure is observed (Fig. 2(c)), which is chiefly due to the temperature gradient formed during the cooling process while being welded. 


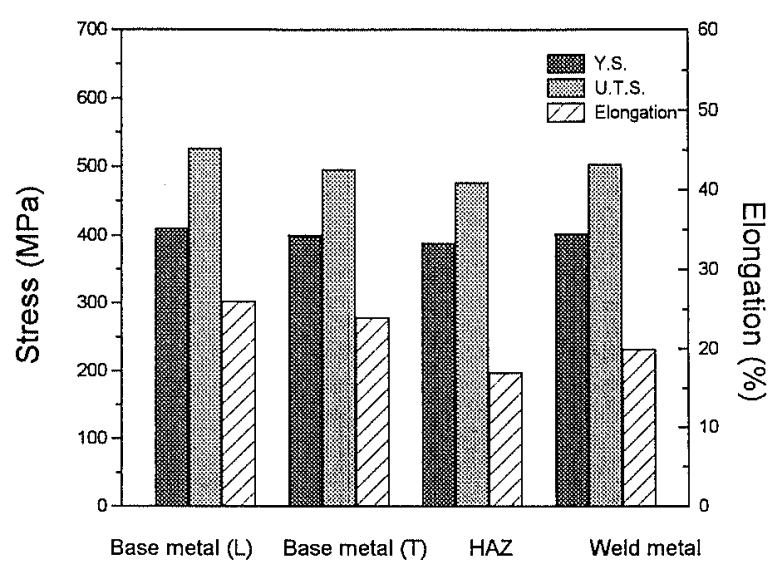

Fig. 3. Tensile properties of the welds in different regions.
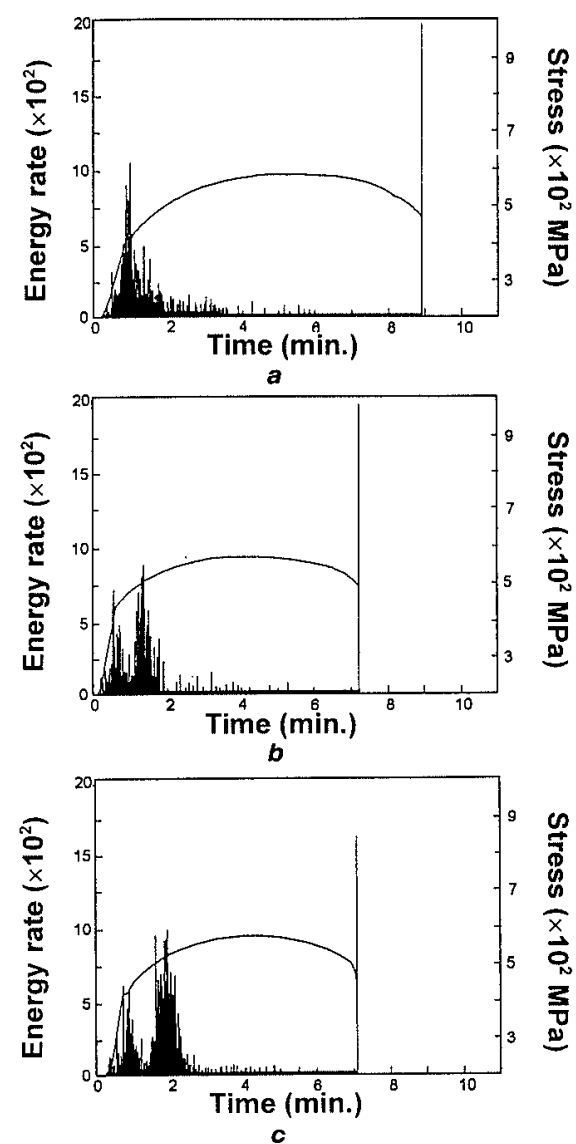

Fig. 4. AE energy rate during tensile tests for specimens in (a) base metal, (B) HAZ and (c) weld metal.

Figure 3 shows the tensile properties of specimens representing the base metal, the $\mathrm{HAZ}$ and the weld metal, respectively. For the base metal, the strength and elongation are slightly higher in longitudinal (L) direction than in transverse $(\mathrm{T})$ direction. For the specimens in the HAZ, the yield strength (Y.S.) is about $9 \%$ lower and the elongation is about $15 \%$ lower than the base metal, presumably due to the grain coarsening and the transformed constituents-induced embrittlement. In the weld metal, the elongation is about $10 \%$ lower than the base metal, which is probably caused by the structural inhomogeneity occurring in the coarse columnar solidification area or in the segregated central area.

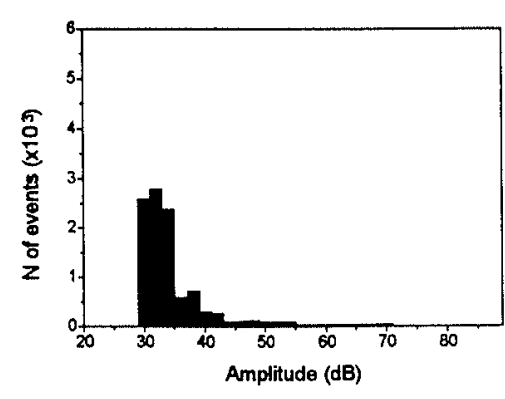

a

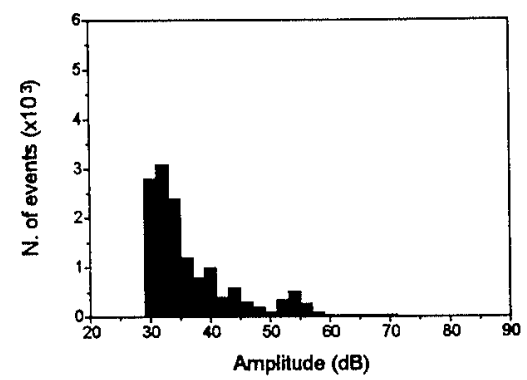

b

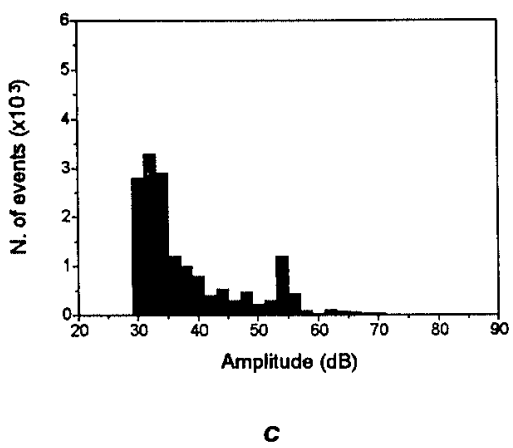

Fig. 5. AE amplitude distribution measured for specimens in (a) base metal, (b) HAZ and (c) weld metal.

\subsection{AE Characteristics of the Welds}

As one of the main AE parameters, the AE energy rate (frequently represented as a root-mean-square voltage) measured during the tensile tests is shown in Fig. 4 together with the corresponding tensile curve, for the specimens representative of different regions in the welded joint. In the base metal (Fig. 4(a)), most of the AE events occur around the yielding stage and the energy rate peak is detected around the yield point. By contrast, the AE behavior in the HAZ and the weld metal is quite different from that in the base metal. As is seen in Figs. 4(b)-4(c), the AE events are evidenced not only around the yield point, but also in the post-yielding stage. A second and higher peak of the AE energy rate is detected in the post-yielding stage. In an earlier review of Heiple and Carpenter ${ }^{10}$ ) it has been well documented that plastic deformation of most structural alloys generates acoustic emission that reaches a maximum at or near the yield stress and diminishes with work hardening. Considering the above general trend, our result is of great interest to note.

Figure 5 shows the $\mathrm{AE}$ amplitude distribution for the tensile specimens taken from different regions of the welds. These plots have been made by post-processing 

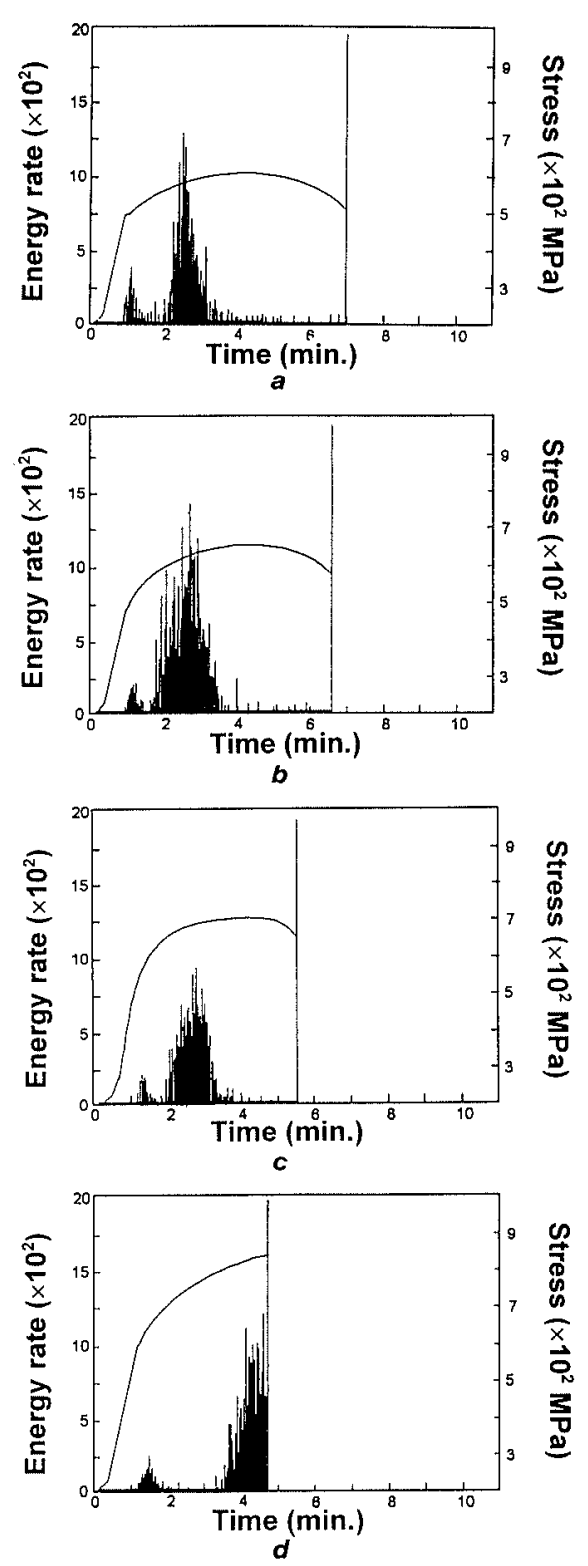

Fig. 6. AE energy rate during tensile tests for specimens with different martensite volume fractions of (a) $26 \%$, (b) $43 \%$, (c) $61 \%$ and (d) $82 \%$.

of AE data. Only amplitudes above $30 \mathrm{~dB}$ are plotted due to the threshold set at this value. It is found that, for all the three regions, most $\mathrm{AE}$ events occur around the yield point but with relatively low amplitudes (30$35 \mathrm{~dB})$. For the specimens of base metal, events with high amplitude (or energy) have rarely been observed to occur. However, for the specimens in the HAZ and the weld metal, the $\mathrm{AE}$ events with higher amplitudes (typically around $54 \mathrm{~dB}$ ) have been evidenced (Figs. 5(b)-5(c)), in contrast to the case in the base metal. Therefore, it is considered from Figs. 4 and 5 that the base metal produces the most of $\mathrm{AE}$ events around the yield point and they are the events of low amplitude $(30-35 \mathrm{~dB})$. For the specimens in the HAZ and the weld metal, the second $\mathrm{AE}$ peak has also been generated in the post-yielding stage and they are the type of high amplitude $(\approx 55 \mathrm{~dB})$.

\subsection{The Origin of the 2nd AE Peak}

For most metals and alloys, a large amount of $\mathrm{AE}$ signals are detected around the yield point and the origin

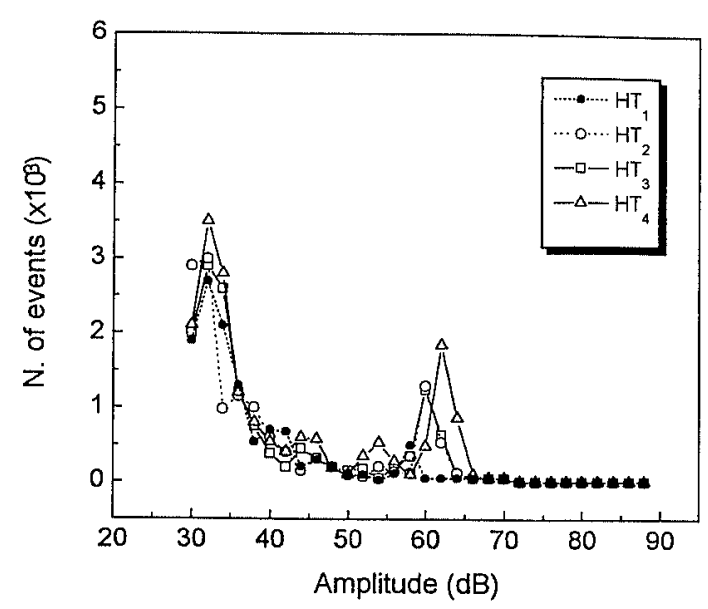

Fig. 7. AE amplitude distribution for specimens heat-treated to have different martensite volume fractions of $26 \%$ $\left(\mathrm{HT}_{1}\right), 43 \%\left(\mathrm{HT}_{2}\right), 61 \%\left(\mathrm{HT}_{3}\right)$ and $82 \%\left(\mathrm{HT}_{4}\right)$.

is generally attributed to the dislocation movement. For instance, it is found by Scruby ${ }^{18)}$ that the AE signals due to the dislocation movement reach to the maximum near the yield point and then gradually decrease. In view of similar AE features, the AE peak around the yield point for the present cases is also assumed to be related to the onset of large amount of dislocation movements. On the other hand, the 2nd AE peak has also been documented in some previous investigations ${ }^{6,7,10-12,19,20)}$ and its origin has been identified as the interaction of moving dislocations with precipitates, ${ }^{6.7)}$ the serrated flow ${ }^{20)}$ and the debonding of second phase particles or inclusions or precipitates from the matrix. ${ }^{10-12.19)}$ Considering the present microstructural constitution, it is highly probable that the 2nd AE peak appearing in the HAZ and the weld metal might be attributed to the existence of martensite. It appears that the nature of the 2 nd peak is different from that of the 1 st peak since the former consists of higher energy events as compared to the latter. Therefore, it is reasonably thought that the 2 nd peak is associated with the micro-cracking at the ferrite-matrix interfaces and/or inside the martensite plates in the post-yielding stage. To examine this assumption, the $\mathrm{AE}$ investigations have further been conducted on another batch of TMCP steel samples heat-treated to result in different amount of martensite.

The AE energy rate variation during the tensile tests is shown in Fig. 6 for the specimens with different martensite volume fractions of $26,43,61$ and $82 \%$. It is found that all the heat-treated specimens exhibit a 2 nd peak of AE energy rate in the post-yielding stage, similar but having different amplitude ratios $\left(A_{1 \text { sl peak }} / A_{2 \text { nd ocak }}\right)$ to the cases in the HAZ and the weld metal of the welded joints (Figs. 4(b)-4(c)). The AE amplitude distribution has also been analyzed for the heat-treated specimens and the results are given in Fig. 7. As is indicated in this figure, in addition to the low-amplitude heavy AE activities occurring around the yield point, there are quite a lot of $\mathrm{AE}$ events occurring at amplitudes higher than $50 \mathrm{~dB}$, characteristic of the second AE peak. The general trend for the second peak of the heat-treated specimens is that the amplitude and the number of events both 

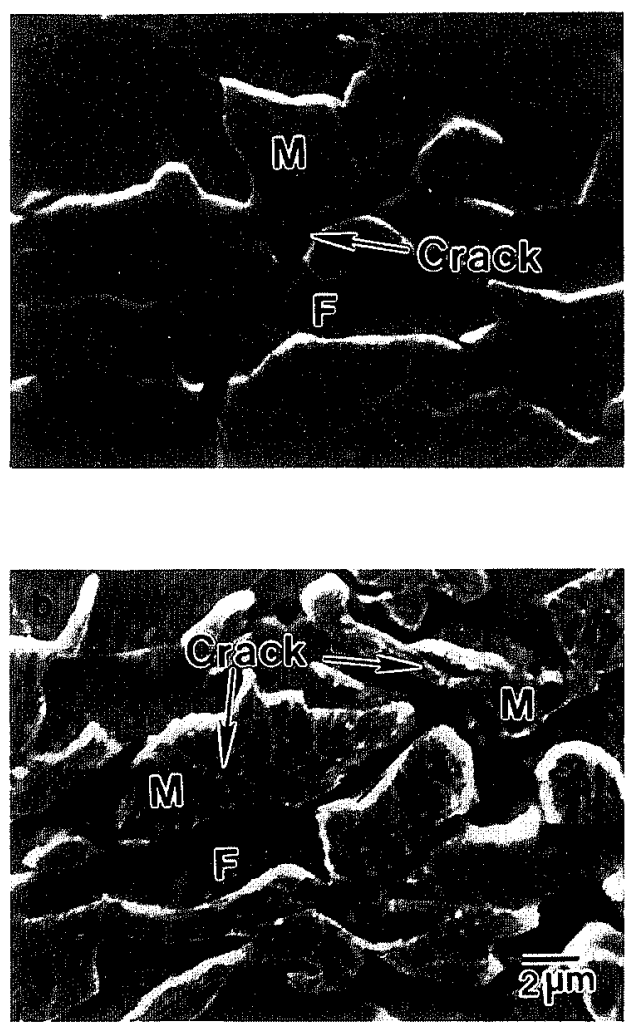

Fig. 8. SEM micrographs showing cracks (a) at the ferrite-martensite interface and (b) inside the martensite for heat-treated specimens after tensile tests.

increase with increasing the volume fraction of the martensite. Comparing Fig. 4 with Fig. 6, it is evident that the volume fractions of martensite present in the $\mathrm{HAZ}$ and weld metal are much less than $26 \%$ since the amplitude ratio of 1 st peak to $2 \mathrm{nd}$ peak is much larger than that of specimen with $26 \%$ martensite. As an example, Fig. 7 shows the SEM micrographs taken from the tensile specimens of the heat-treated steel. It is evidenced that microcracks can be found both at the ferrite-martensite interface (Fig. 8(a)) and in the interior of martensite (Fig. $8(\mathbf{b})$ ). Combining with the $\mathrm{AE}$ characteristics shown above, it is justified that the occurrence of the 2nd AE peak is attributed to the existence of the martensite in which the micro-cracking events occur due to the ferrite-martensite interfacial debonding and/or the martensite plate cracking itself. This point is supported by a previous AE investigation on the carburized steels, ${ }^{21)}$ which identifies the 2 nd AE peak with higher amplitude as originated from the intergranular cracking. It should also be noted that, although the 2 nd AE peak detected by another previous investigation $^{22)}$ is attributed to the breakaway of dislocations from pins created by the deformation process, the corresponding amplitudes are much lower than those of the lst peak, in contrary to the order of the amplitude distribution found in the present investigation.

The difference in the strength level between ferrite and martensite is assumed to be mainly responsible for the cracking via the ferrite-martensite interfacial debonding. Moreover, the residual stresses resulted from the inhomogeneous contraction due to cooling and expansion during martensitic transformation may also con-

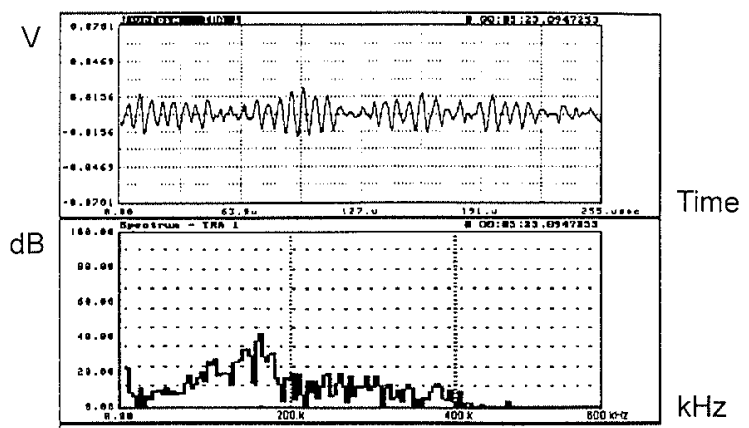

a

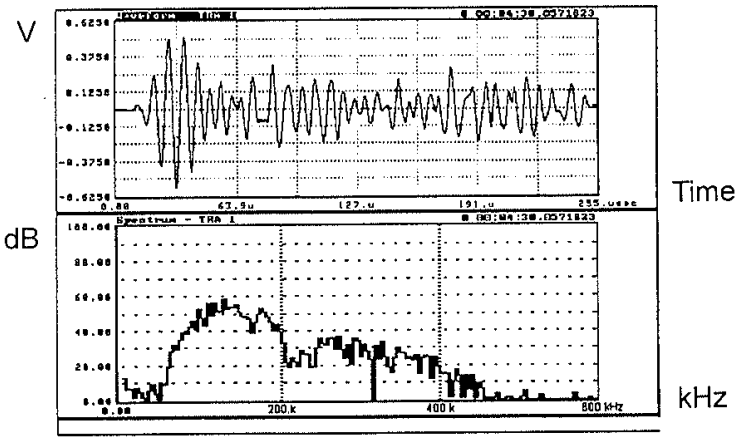

Fig. 9. AE waveform (upper part) and frequency spectrum (lower part) for (a) ferrite deformation and (b) ferrite-martensite interface cracking.

tribute to the interfacial cracking. Therefore the interface is highly susceptible for the initiation of microcracks and hence, the $\mathrm{AE}$ from these regions possesses an evidently higher energy than in the case where just plastic deformation occurs. For the heat-treated specimens with various martensite contents, the 1 st $\mathrm{AE}$ peak around the yield point is obviously lower than the 2nd peak (Fig. 6). This is probably due to the Kaiser effect ${ }^{3)}$ since, during the heat-treatment, the inhomogeneous contraction causes local plastic deformation with which the Kaiser effect may happen.

\subsection{Fast Fourier Transformation (FFT) Analysis}

Frequency spectrum analysis has the advantage of being able to distinguish and characterize different types of sources operating during deformation because different deformation or damage processes usually correspond to different frequency spectrum. ${ }^{13)}$ The FFT method is a good tool for the frequency spectrum analysis and is employed in the present study to analyze the AE signals detected in the specific cases of the ferrite deformation and the ferrite-martensite interfacial cracking. The results are given in Fig. 9 as typical examples. The upper and lower diagrams of Figs. 9(a) and 9(b) show the waveform of a particular event and its frequency spectrum, respectively. Fig. 9 (a) represents the data of base metal in which only the 1 st $\mathrm{AE}$ peak has been generated due to the ferrite deformation, while Fig. 9(b) shows the data of higher energy events, which is mainly responsible for the 2 nd peak in the heat-treated specimens. This higher energy event can be clearly distin- 
guished with the low energy event in the heat-treated specimens, due to the large difference (by the order of magnitude difference) in their amplitude (energy) levels. In the case of ferrite deformation, the AE wave is a type of long rise time (rise time $=$ the time required to reach the maximum amplitude) and low amplitude. This is in accordance with the present fractographic observation that the base metal fractures in a typical ductile mode. The frequency corresponding to the peak is about $175 \mathrm{kHz}$, and the maximum peak amplitude reaches to $0.02 \mathrm{~V}$. By contrast, for the event of the 2 nd AE peak (presumed due to the ferrite-martensite interfacial cracking), the $\mathrm{AE}$ wave shows a type of short rise time and high amplitude. This is also in agreement with the fact that a brittle fracture occurs with a high energy releasing rate in the steel with the martensitic microstructure. The frequency for the peak is about $110 \mathrm{kHz}$, obviously lower than in the case of ferrite deformation, and the maximum peak amplitude reaches to $0.5 \mathrm{~V}$. A previous frequency spectrum analysis of AE for an AISI 316 type stainless steel ${ }^{13)}$ has indicated that, while the characteristic frequency associated with uniform plastic deformation is detected to fall in the range of $470-660$ $\mathrm{kHz}$ increasing linearly with strain level, the characteristic frequency associated with the micro-void coalescence and/or crack growth has an evidently lower value of about $140 \mathrm{kHz}$. This frequency shifting tendency, from a higher frequency characterizing the uniform deformation to a lower frequency characterizing the cracking behavior, is basically consistent with the present results on the frequency spectrum analysis as shown in Fig. 9, although the absolute values of the characteristic frequencies are different, due to different alloy systems.

\section{Concluding Remarks}

In the present investigation, the acoustic emission behavior during the tensile tests of three different regions of low carbon steel welds have been examined, and the following conclusions have been made.

(1) In the base metal region of the weld joint, most $A E$ events are associated with the dislocation movement during the yielding and only one AE peak consisting of low energy events is found around the yield point. In the HAZ and the weld metal, in addition to the 1st AE peak around the yield point, a 2 nd peak composed of high energy events appears in the post-yielding stage and is presumed to associate with the microcracking events occurring at the ferrite-martensite interface and/or within the martensite.

(2) The AE behavior of the heat-treated steel with different martensite contents is also characterized by the existence of the 2nd AE peak. Both the AE amplitude and the number of events increase as the volume fraction of martensite increases. Cracks are found at the ferritemartensite interface and/or in the interior of martensite.

(3) In the case of ferrite matrix deformation, the AE signal shows a waveform of long rise time and low amplitude, and the peak of frequency spectrum occurs at a relatively high frequency $(\approx 170 \mathrm{kHz})$. However, when the ferrite-martensite interfacial cracking occurs, the waveform is characterized by a short rise time and an order of magnitude higher amplitude than the former, and the frequency peak occurs at a lower frequency $(\approx 110 \mathrm{kHz})$.

\section{Acknowledgments}

The present work is financially supported by Pohang University of Science and Technology (POSTECH). The authors are thankful to Pohang Iron \& Steel Co. Lrd. (POSCO) for supplying the TMCP steel plates. The authors are also grateful to Dr. H. D. Jeong (RIST) for his assistance in the welding experiment and for the fruitful discussion.

\section{REFERENCES}

1) A. J. DeArdo: Proc. of Int. Conf. on Microalloying, Iron and Steel Society, Pittsburgh, (1995), 15.

2) T. Haze, S. Aihara and H. Mabuchi: Accelerated Cooling of Rolled Steel, TMS, Warrendale, (1986)

3) Non-Destructive Testing Handbook, 2nd Edition, Vol. 5, American Society for Non-Destructive Testing, Columbus, (1981).

4) H. N. G. Wadley, C. B. Scruby, P. Lane and J. A. Hudson: Met Sci., 15 (1981), 514.

5) T. J. C. Webbor and R. D. Rawlings: Met. Sci.. 15 (1981), 533.

6) B. Scruby, H. N. G. Wadley and K. L. Rusbridge: Mater. Sci. Eng., 59 (1983), 169.

7) J. R. Kennedy: J. Mater. Sci., 18 (1984), 286.

8) K. J. Hong, H. D. Jeong and C. S. Lee: J. Acous. Emiss., 13 (1995), S61.

9) K. A. Lee and C. S. Lee: Mater. Sci. Eng. A, 229 (1997), 219

10) C. H. Heiple and S. H. Carpenter: J. Acoust. Emiss., 6 (1987), 117

11) Z. H. Zhu and S. H. Carpenter: J. Acoust. Emiss., 6 (1987), 115

12) S. M. Cousland and C. M. Scala: Mater. Sci. Eng., 57 (1983), 23.

13) B. Raj, B. B. Jha and P. Rodriguez: Acta Metall., 37 (1989), 2211

14) J. M. Whittaker and M. W. Richey: J. Acoust. Emiss., 6 (1987), 257.

15) C. B. Scruby and K. A. Stacey: J. Acoust. Emiss., 7 (1988), 81

16) P. G. Bentley and M. J. Beesley: J. Acoust. Emiss., 7 (1988), 59

17) R. E. Dolby: Metals Technology, 10 (1983), 349.

18) C. Scruby, H. Wadley and J. E. Sinclair: Phil. Mag., 44A (1981), 249

19) M. Wu and S. H. Carpenter: J. Acoust. Emiss., 11 (1983), 5.

20) Y. Xu, Z. Zou and F. Du: Phys. Stat. Sol., A155 (1996), 305.

21) B. Raj and T. Tayakumar: J. Acoust. Emiss., 7 (1988), SI.

22) C. H. Heiple and S. H. Carpenter: J. Acoust. Emiss., 9 (1990), 1. 